\title{
Editorial
}

\section{Topical Issue on Solidification}

It is a real pleasure to present to the Readers of the Metallurgical Research \& Technology, formerly Revue de Métallurgie, a selection of five papers dedicated to Solidification.

These papers have been written after the European Congress and Exhibition on Advanced Materials and Processes (Euromat) held in Sevilla, Spain, from Sept. 8th to 13th, 2013. They were presented at the symposium Solidification which aimed at reviewing recent developments in the field of solidification from both experimental and theoretical points of views. About 100 people gathered at the session with 38 oral presentations and about 20 posters. Different topics were discussed such as processes, mushy zone dynamics, microstructure and defects analyzed with the help of modern materials science and engineering tools e.g. modeling and in situ observations. The emphasis was placed on nucleation and growth kinetics, rapid solidification, phase competition, dendritic, eutectic and peritectic microstructures, porosity, residual stresses, distortions, hot tearing, microand macro-segregation. Aspects related to solidification of ceramic materials and glasses were also adressed. The symposium was organised by J.-M. Drezet from Ecole Polytechnique Lausanne (Switzerland) and J.-I. Peña from the university of Zaragoza (Spain). The Euromat congress takes place every other year in Europe and is organised by the Federation of European Materials Societies (FEMS, http://www.fems.org/). The following five papers give a good idea of the topics addressed during the symposium. Molecular dynamics starts to tackle specific solidification issues and appears to be a promising tool in the future though it is limited at the moment to pure elements. The authors of these five papers are heartfully thanked for accepting to present their work in our journal. 